See Article page $\mathrm{XXX}$.

\section{Commentary: Isolated tricuspid valve regurgitation: The worst is yet to come, so act now!}

\author{
Ettorino Di Tommaso, MD, and \\ Vito D. Bruno, MD, $\mathrm{PhD}$
}

Nowadays, isolated tricuspid valve (TV) surgery is still an undefined entity and although tricuspid diseases are increasing in the population, isolated surgical procedures on this valve remain low across cardiac centers, with patients more often referred to centers for decompensated tricuspid regurgitation (TR). ${ }^{1}$ This mainly relates to the poorer outcomes and the greater mortality rates that TV surgery has compared with the other single-valve operations. Many studies show a perioperative mortality close to $10 \%$, with certain series showing a 1 -year mortality up to $24 \%{ }^{2}$ Although most cardiac surgical operations are trending to lower risks of mortality and morbidity, TV surgery still plays the role of the disappointing child of the family. The current guidelines are not univocal, with the American College of Cardiology/American Heart Association having not recommended class I indications for isolated TV regurgitation, whereas the European Society of Cardiology guidelines have only one class I indication for severe symptomatic TR. ${ }^{3,4}$ In this contest, only patients with severe right heart symptoms (ascites, leg swelling, dyspnea) are referred to the surgeon, with obvious implications on the results and outcomes of these patients after surgery.

In the current issue of the Journal, Wang and colleagues ${ }^{5}$ compared the characteristics and outcomes of isolated TV surgery in patients with class I indications

\footnotetext{
From Translational Health Science, University of Bristol Medical School, Bristol, United Kingdom.

Disclosures: The authors reported no conflicts of interest.

The Journal policy requires editors and reviewers to disclose conflicts of interest and to decline handling or reviewing manuscripts for which they may have a conflict of interest. The editors and reviewers of this article have no conflicts of interest.

Received for publication July 31, 2021; revisions received July 31, 2021; accepted for publication Aug 3, 2021.

Address for reprints: Vito D. Bruno, MD, PhD, Research Floor Level 7, Queens Building, Bristol Royal Infirmary, Upper Maudlin St, BS2 8HW, Bristol, United Kingdom (E-mail: vito.d.bruno@bristol.ac.uk).

J Thorac Cardiovasc Surg 2021; $: 1-2$

0022-5223/ $\$ 36.00$

Copyright (C) 2021 by The American Association for Thoracic Surgery

https://doi.org/10.1016/j.jtcvs.2021.08.010
}

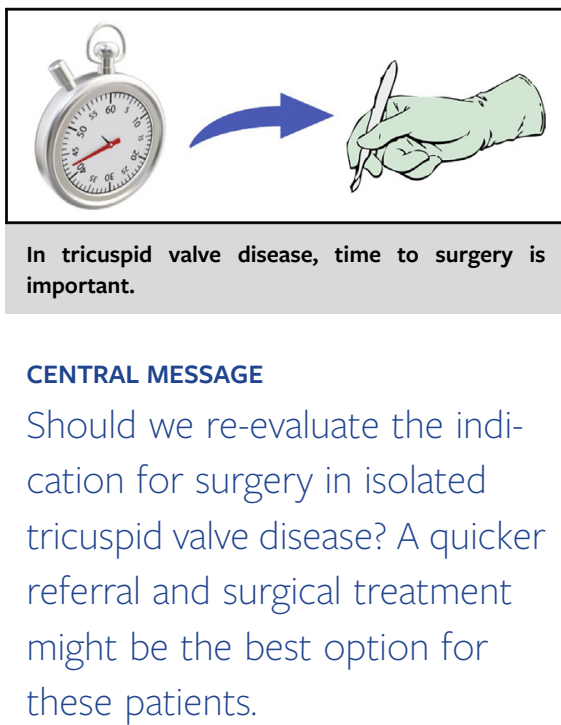

of severe symptomatic TR versus those without (early surgery). The authors aimed to evaluate the beneficial effects of anticipated surgery on patients without symptoms attributable to severe TR. The conclusion of their study is a simple but effective message: do not wait for the worst. Over a period of 14 years, they selected 159 patients undergoing isolated TV surgery (115 in Class I and 44 not in Class I) and analyzed early and late outcomes. The early surgery group had significantly better results in both short and long term, with an astounding difference in the short-term mortality rates $(0 \%$ vs $7 \%)$ and a significantly better hazard ratio for the long-term survival, even when adjusted for covariates. The patients in class I also had greater morbidity rates than those in the early surgery group $(35.7 \%$ vs $18.2 \%, P=.036)$. Although there are some noticeable differences in the clinical characteristics of the 2 groups, with the ones in class I being older, more symptomatic, and with greater New York Heart Association class, the findings of this study are interesting. The idea of performing surgery for valve disease before the patient reaches a decompensated state is intuitive, and it has already been partially applied to aortic and mitral valve surgery. In this case, the authors were able to demonstrate an obvious advantage of the early surgery in isolated TV disease, supporting a more proactive approach toward the intervention even for these patients. Moreover, the importance of repairing the valve instead of replacing it is well highlighted by the paper. The results are even more significant considering the high-volume center in which the study was conducted and the insights these findings can provide to the newer catheter-based approaches for TR. ${ }^{6}$ Being able to 
recognize the patients with severe TR who will benefit from early treatment before they become clinically symptomatic is the critical message the authors want to convey. Medical treatment is an essential instrument in slowing the disease progression, but unfortunately, this is frequently characterized by a failure of response to diuretics with signs of severe right heart dysfunction and decompensation.

The development of symptoms related to TR is subtle, and once established, the surgery is the only available option, despite the high rates of mortality and rehospitalization. ${ }^{7}$

Despite the obvious benefits of the study by Wang and colleagues, ${ }^{5}$ some concerns could be raised, from the small sample size they presented and the high variability that the elevated number of surgeons performing the operations could have generated. Limitations are evident in the patients' preoperative characteristics between the 2 groups, which can likely explain the differences in their outcomes. These should not invalidate the results of Wang and colleagues, which are opening the door to a possible new era for the treatment of TV pathology.
And, hopefully, the moniker of "forgotten valve" will be a distant memory.

\section{References}

1. Zack CJ, Fender EA, Chandrashekar P, Reddy YNV, Bennett CE, Stulak JM, et al. National trends and outcomes in isolated tricuspid valve surgery. J Am Coll Cardiol. 2017;70:2953-60.

2. Kundi H, Popma JJ, Cohen DJ, Liu DC, Laham RJ, Pinto DS, et al. Prevalence and outcomes of isolated tricuspid valve surgery among Medicare beneficiaries. Am J Cardiol. 2019;123:132-8.

3. Falk V, Baumgartner H, Bax JJ, De Bonis M, Hamm C, Holm PJ, et al. 2017 ESC/ EACTS guidelines for the management of valvular heart disease. Eur J Cardiothorac Surg. 2017;52:616-64.

4. Otto CM, Nishimura RA, Bonow RO, Carabello BA, Erwin JP III, Gentile F, et al. 2020 ACC/AHA guideline for the management of patients with valvular heart disease: executive summary: a report of the American College of Cardiology/American Heart Association Joint Committee on clinical practice guidelines. Circulation. 2021;143:e35-71.

5. Wang TKM, Akyuz K, Xu B, Gillinov A, Pettersson GB, Griffin BP, et al. Early surgery improves long-term survival compared to class I indication for isolated severe tricuspid regurgitation. J Thorac Cardiovasc Surg. July 30, 2021 [Epub ahead of print].

6. Bapat V, Tang GHL. Emerging transcatheter options for tricuspid regurgitation: many shades of gray. J Thorac Cardiovasc Surg. 2020;160:1460-4.

7. Russo M, Zilberszac R, Werner P, Kocher A, Wiedemann D, Schneider M, et al. Isolated tricuspid valve regurgitation: old concepts, new insights and innovation. J Cardiovasc Med. 2020;21:406-14. 